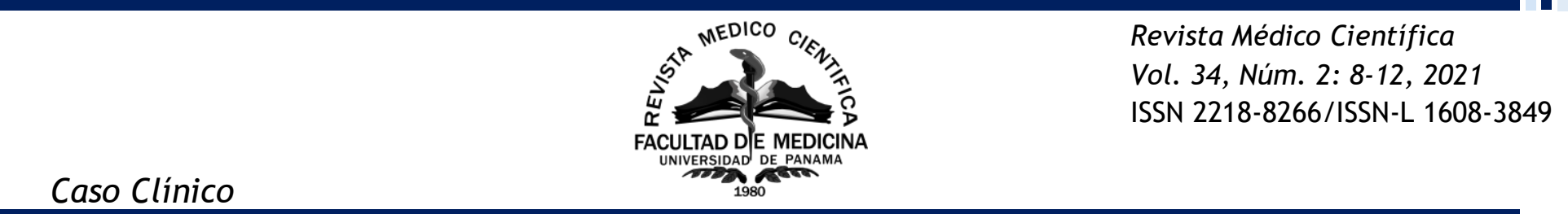

\title{
¿Embarazo o teratoma? Reporte de un caso
}

\author{
Pregnancy or teratoma? A case report \\ Angelique Orillac-DeObaldia (i)*, Pave Mislov-Vallarino ***, \\ Yassiel Pineda-Aguilar@†, Samuel Moreno-Wynter®* \\ * Médico Interno de Segunda Categoria del Hospital Santo Tomás, Panamá \\ † Médico Interno de Segunda Categoría del Complejo Hospitalario Dr. Arnulfo Arias Madrid, Panamá
}

\section{RESUMEN}

El siguiente caso fue desarrollado en el Complejo Hospitalario Doctor Arnulfo Arias Madrid en la Ciudad de Panamá. Se trata de un reporte de caso de una masa anexial de gran tamaño en una paciente joven que presenta un antecedente reciente de un aborto, por lo cual amerita un estudio más profundo para descartar otro diagnóstico o malignidad. La masa causa dolor severo, incomodidad estética y funcional a la paciente además de una elevación importante de la hormona gonadotropina coriónica humana, la cual se utiliza como marcador de embarazo y malignidades. Tras extensa intervención quirúrgica, se extirpa una masa de $21 \times 17 \times 13 \mathrm{~cm}$, se reparan las estructuras afectadas y se confirma por patología el diagnóstico de teratoma maduro quístico.

\section{ABSTRACT}

The following case was developed at Hospital Dr. Arnulfo Arias Madrid in Panama City. This is a case report of a large adnexal mass in a young patient with a recent history of abortion, therefore requiring a more in-depth study to rule out malignancy. The mass causes pain and esthetic and functional discomfort to the patient as well as a significant elevation of human chorionic gonadotropin hormone, which is used as a marker for pregnancy and malignancies. After extensive surgery a $21 \times 17 \times 13 \mathrm{~cm}$ mass is removed, and adjacent affected structures are repaired. The mass is sent in for pathologic evaluation, which confirms the diagnosis of mature cystic teratoma.
Correspondencia: smorenomd@gmail.com Recibido: 24/12/19 Aceptado: 28/11/20

PALABRAS CLAVE:

Teratoma, neoplasias pélvicas, cáncer de ovario.

KEY WORDS:

Teratoma, adnexal disease, ovarian neoplasm.

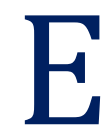

I teratoma maduro según el Instituto Nacional de Cáncer se define como un "tipo de tumor de células germinativas que suele estar compuesto de distintos tipos de tejido como pelo, músculo y hueso". Se consideran maduros porque tienen células semejantes a las células normales. Algunos teratomas maduros generan enzimas u hormonas. ${ }^{[1,2,3]}$ El manejo de los teratomas maduros es la extracción quirúrgica del mismo. 
ENFERMEDAD ACTUAL

Paciente femenina de 19 años que es referida al Complejo Hospitalario Dr. Arnulfo Arias Madrid para efectuarse laparotomía exploratoria por tumoración anexial de $21 \mathrm{~cm}$ de diámetro.

La paciente refiere dolor tipo cólico en fosa ilíaca izquierda con intensidad 8/10 sin irradiación, que se agrava con la bipedestación y el decúbito supino y prono. Refiere tomó naproxeno $550 \mathrm{mg}$, pero no brindó alivio. El dolor está asociado a un aumento del perímetro abdominal de 11 meses de evolución.

Refiere periodos menstruales regulares sin alteraciones por patología de base. Niega pérdida de peso, sangrado uterino anormal, fiebre o sensación de llenura postprandial.

\section{HISTORIA ANTERIOR}

Paciente niega patologías previas, alergias, o transfusiones. Refiere menarquia a los 14 años, inicio de vida sexual activa a los 16 años y solo ha estado con 1 pareja sexual. Niega hábitos de consumo como alcohol, tabaco o drogas.

Hace 6 meses se le realizó una aspiración manual endouterina (AMEU) por aborto incompleto de 8 semanas de gestación.

Refiere como antecedentes heredofamiliares hipertensión arterial en su madre y abuela materna.

Extrahospitalariamente fue tratada con naproxeno 550 mg por vía oral (VO) según necesidad e intrahospitalariamente con cefalotina $2 \mathrm{~g}$ por vía intravenosa (IV). En el preoperatorio se administró ranitidina $10 \mathrm{mg} \mathrm{IV}$, lisalgil $2 \mathrm{~g} \mathrm{IV}$, acetaminofén $1 \mathrm{~g} \mathrm{IV}$, metoclopramida $10 \mathrm{mg}$ IV durante 48 horas previa a la cirugía.

\section{REVISIÓN POR APARATOS Y SISTEMAS}

Refiere dolor en bajo vientre tipo cólico. Niega trastornos menstruales como amenorrea, dismenorrea o menorragia, niega infecciones genitales. Paciente no se ha realizado prueba de Papanicolaou. Niega pérdida de peso o llenura postprandial. Resto sin datos de relevancia.

\section{EXAMEN FÍSICO}

Al examen físico la paciente se encuentra consciente, alerta, orientada en las tres esferas, con presión arterial de $130 / 80 \mathrm{mmHg}$, temperatura de $36 \circ \mathrm{C}$, frecuencia cardíaca de 76 latidos por minuto $y$ frecuencia respiratoria de $18 \mathrm{rpm}$, mamas sin masas palpables ni lesiones visibles, abdomen de aspecto globoso, duro a la palpación e impresiona una masa gigante adherida a planos profundos. Resto del examen físico sin alteraciones.

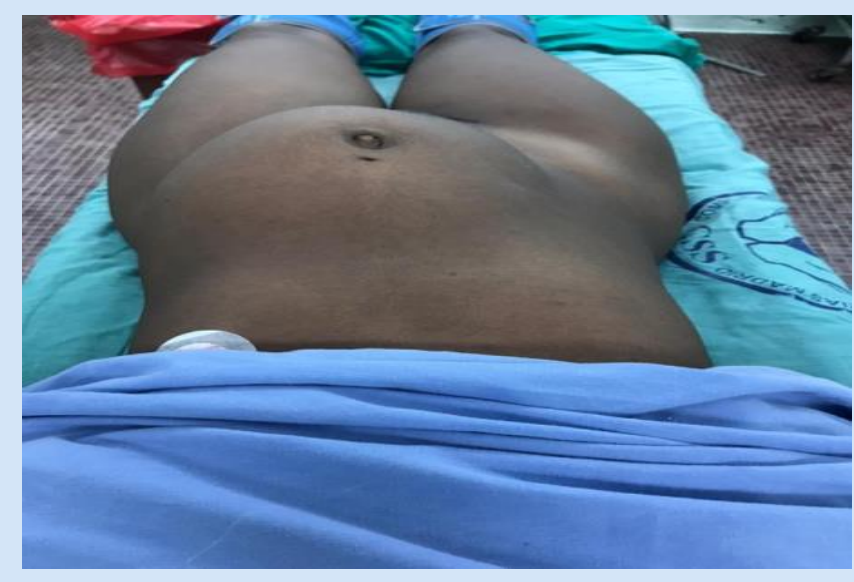

Figura 1. Abdomen globoso

Se observa un abdomen globoso a expensas de una masa de predominio en hemiabdomen izquierdo

Fuente: Servicio de Ginecología y Obstetricia del Hospital Metropolitano Arnulfo Arias Madrid de la Caja de Seguro Social, 2019. 


\section{ESTUDIOS DE LABORATORIO}

Se envía marcadores tumorales antígeno carcinoembrionario (CAE) con resultado de 5.13 $\mathrm{ng} / \mathrm{mL}(0.0-4.7 \mathrm{ng} / \mathrm{mL})$. Alfa feto proteína y antígeno del cáncer 125 (CA-125) dentro de límites normales. Gonadotropina coriónica humana fracción beta $\begin{array}{lllll}\text { (BhCG) cuantitativa } 32 & 914 \mathrm{mUl} / \mathrm{mL} & \text { (0.0-7.7 }\end{array}$ $\mathrm{mUl} / \mathrm{mL}$ ), por lo que se piensa en tumoración de células germinales vs una enfermedad de trofoblasto asociado a su antecedente de aborto evacuado.

Otros laboratorios como biometría hemática completa $(\mathrm{BHC})$, urinálisis, química general, inmunoquímica para el virus de la inmunodeficiencia humana (VIH) y Treponema pallidum no demostraron datos relevantes.

\section{ESTUDIOS DE IMAGEN}

Se realiza un ultrasonido abdominal, el cual revela una masa en el anexo izquierdo que cuenta con un contenido heterogéneo y mide aproximadamente $21 \mathrm{~cm}$. Estos hallazgos orientan el diagnóstico de la masa anexial y, al ser sintomática, de consistencia heterogénea y con elevación de marcadores tumorales, se recomienda el abordaje quirúrgico.

Además, se realiza una tomografía, la cual reporta una lesión ovárica con bordes definidos, heterogénea con mayor componente quístico, contenido calcificado, septada y sin refuerzo con el contraste. La misma mide 21.24 x $13.31 \times 17.51 \mathrm{~cm}$ ( $L$ x AP x T). Las características son concordantes con un teratoma.

\section{TRATAMIENTO}

\section{Se realiza laparotomía exploratoria,} salpingooforectomía izquierda, linfadenectomía pélvica lateral y paraaortocava, reparación de arteria aorta, legrado uterino instrumentado.
En la cirugía se encuentra tumoración sólida nacarada con alta vascularización dependiente de anexo izquierdo de $+/-20 \times 12 \mathrm{~cm}$, útero de $11 \mathrm{~cm}$ globoso de aspecto sano, con adenopatía paraaórtica sospechosa de $1 \mathrm{~cm}$.

Se envía muestra a patología que reporta diagnóstico de teratoma maduro quístico.

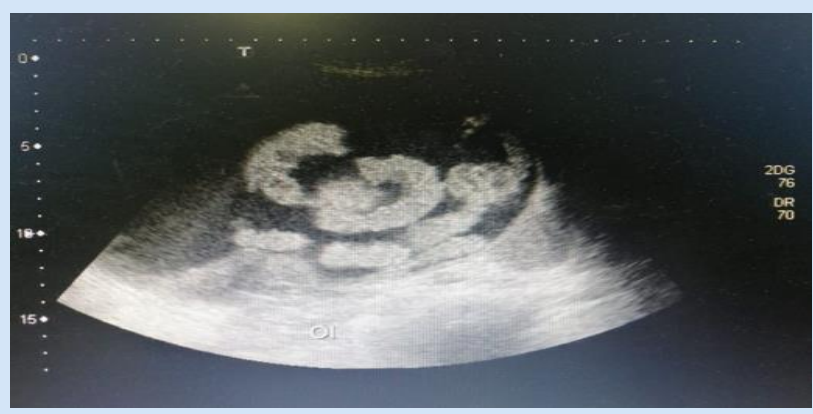

Figura 1. Ecografía abdominal

Se evidencia masa anexial izquierda de contenido heterogéneo que mide aproximadamente $21 \mathrm{~cm}$

Fuente: Servicio de Ginecología y Obstetricia del Hospital Metropolitano Arnulfo Arias Madrid de la Caja de Seguro Social, 2019.
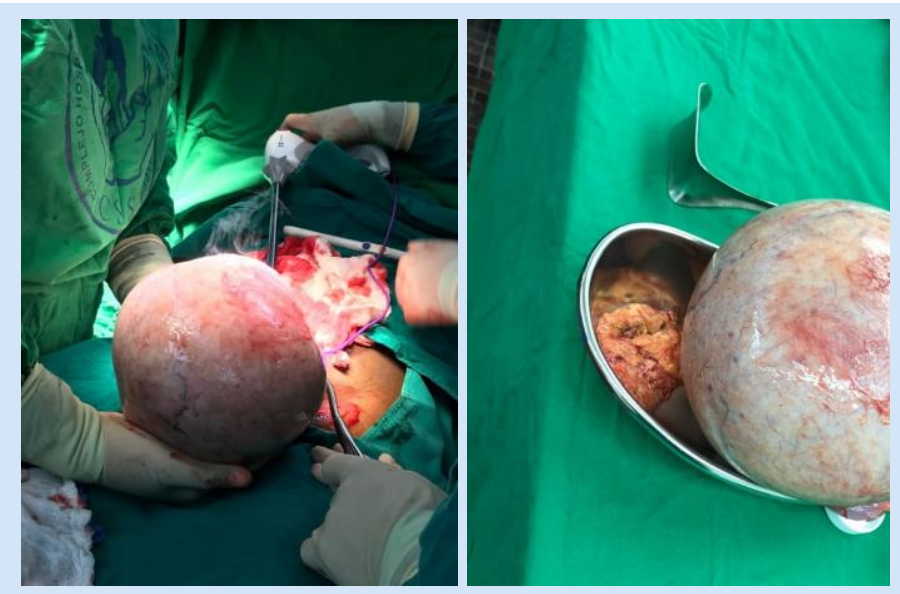

Figura 1. Masa anexial izquierda de $21 \times 13 \times 17 \mathrm{~cm}$

Fuente: Servicio de Ginecología y Obstetricia del Hospital Metropolitano Arnulfo Arias Madrid de la Caja de Seguro Social, 2019. 
DIAGNÓSTICO DIFERENCIAL

1. Cáncer de ovario: descartado debido al estudio histopatológico.

2. Embarazo: descartado por hallazgos ultrasonográficos no concordantes con embarazo.

3. Quiste ovárico simple: descartado debido al estudio histopatológico y características ecográficas de la masa (heterogénea).

4. Mioma / Fibroma uterino: descartado debido a las características del estudio de imagen.

DISCUSIÓN

Los teratomas maduros son la neoplasia de ovario benigna más común que surge de las células germinales del ovario. Se reportan 9 casos por cada 100000 mujeres, de las cuales se afectan principalmente las menores de 45 años. Son de crecimiento lento y se transforman a malignos en un 0.25 a $3 \%$ de los casos. ${ }^{[4,5]}$

Los teratomas maduros se desarrollan por partenogénesis. Las células germinales haploides (posmeióticas) se endorreduplican para dar origen a células tumorales diploides genéticamente femeninas $(46, X X)$. Por lo general estos tumores contienen estructuras bien diferenciadas que provienen de 2 o 3 de las capas germinales. ${ }^{[4]}$

Por lo general, son encontrados como hallazgos incidentales en exámenes físicos o de imagen de las pacientes. En caso de presentar síntomas, estos son inespecíficos como el dolor abdominal, sangrado uterino anormal y sensación de cuerpo extraño o pesado. ${ }^{[6,7]}$

El diagnóstico de la patología se realiza por medio de los exámenes de imágenes como el ultrasonido, el cual es altamente inespecífico. Otras pruebas como la tomografía y la resonancia son de mayor utilidad Rev Méd Cient. 2021;34(2):8-12 ya que estos muestran la grasa intratumoral que es altamente específica de este tipo de tumores. La única forma de confirmar de manera definitiva el diagnóstico es por medio de la biopsia, ya que en la histopatología se demuestran las características de diferenciación propias de un teratoma maduro. De presentar características de baja diferenciación, se considera un teratoma inmaduro, el cual sí es una patología maligna. ${ }^{[4,8]}$

El manejo de estos tumores se reserva para los pacientes que presenten molestias. La resección laparoscópica ha demostrado tener menos morbilidad para los pacientes. Todo teratoma bilateral mayor de $6 \mathrm{~cm}$ que se detecte en el embarazo debe ser removido. En caso tal de dar un manejo conservador, se recomienda realizar seguimiento con ultrasonido cada 6 meses a 1 año. Entre los factores a considerar en los pacientes al intervenir quirúrgicamente están la edad, deseo de fertilidad a futuro y el tamaño del tumor. Las complicaciones más comunes incluyen la torsión anexial, la ruptura espontánea y la transformación maligna del tumor. ${ }^{[4,6,7,9,10]}$

El patólogo, al realizar los cortes de la muestra, determina que se trata de un teratoma maduro, lo cual no representa un riesgo para la vida de la paciente. Además, nos da la certeza que con la cirugía ya se realizó la indicación terapéutica de esta paciente.

CONCLUSIÓN

En pacientes con masas anexiales es importante saber que el primer paso para el diagnóstico de patologías ginecológicas es la adecuada realización de una historia clínica y examen físico, ya que estos son los pasos que nos aportarán más información sobre la patología y, por lo tanto, proporcionarán un manejo adecuado. Los exámenes complementarios como estudios de imagen (ej. Ultrasonido y 
Tomografía computarizada), marcadores tumorales (ej. Gonadotropina coriónica humana y CEA) y exámenes de laboratorio básicos (ej. BHC, química general e inmunoquímica para $\mathrm{VIH}$ ) nos ayudan a orientar a un diagnóstico más específico y descartar otras patologías. El ultrasonido es sin duda una herramienta fundamental de bajo costo y no invasiva para evaluar el origen no solo de la masa sino también su contenido, y así realizar una correcta categorización de la patología y el pronóstico de la misma. Una vez realizado los estudios, el siguiente paso en el manejo es la extracción de la masa. En este caso está indicado la extracción por laparotomía debido a las características y tamaño de la masa; posterior a este procedimiento, la misma debe ser enviada al departamento de patología para el diagnóstico histopatológico adecuado. En el caso de esta paciente el diagnóstico de teratoma maduro fue confirmado.

\section{AGRADECIMIENTOS}

Queremos agradecer a nuestros compañeros Rosangel Montenegro, Mariana Ojeda, Danilo Morales y Nabil Parekh por su apoyo en la breve realización de este caso.

\section{BIBLIOGRAFÍA}

[1] Diccionario de cáncer [Internet]. National Cancer Institute. 2019 [citado 2019 Dic 6]. Disponible en: https://www.cancer.gov/espanol/publicaciones/diccionari o/def/teratoma-maduro

[2] Asale R-, Rae. tumor: Diccionario de la lengua española [Internet]. "Diccionario de la lengua española" - Edición del Tricentenario. [citado 2019 Dic 6]. Disponible en: https://dle.rae.es/tumor

[3] National Comprehensive Cancer Network [Internet]. NCCN Clinical Practice Guidelines in Oncology. [citado 2019 Dic 6]. Disponible en: https://www.nccn.org/professionals/physician gls/defaul t.aspx
[4] Mature Cystic Teratoma of the Ovary [Internet]. DynaMed. [citado 2019 Dic 2]. Disponible en: https://www.dynamed.com/condition/mature-cysticteratoma-of-the-ovary

[5] Cabezas-Palacios MN, Rodríguez-Zarco E, RodríguezJiménez I, Márquez-Maraver F. Teratoma ovárico maduro e inmaduro, a propósito de un caso. Ginecol. obstet. Méx. [revista en la Internet]. 2017 [citado 2019 Dic 15] ; 85(5): 331-337. Disponible en: http://www.scielo.org.mx/scielo.php?script=sci_arttext\&p $\mathrm{id}=\mathrm{S} 0300-90412017000500331 \& \operatorname{lng}=\mathrm{es}$

[6] Rubin R, Strayer DS, Rubin E. Rubin Patología: fundamentos clinicopatológicos en medicina: sexta edición. Barcelona: Wolters Kluwer Health/Lippincott Williams \& Wilkins; 2012 P. 897-890

[7] Pinheiro P. TERATOMA OVÁRICO - Tipos, síntomas y tratamiento " MD.Saúde [Internet]. MD.Saúde. MD.Saúde; 2019 [citado 2019 Dic 15]. Disponible en: https://www.mdsaude.com/es/ginecologia-es/teratomaovaricol

[8] Chappelear A. Germ Cell Tumors [Internet]. Johns Hopkins Pediatric Oncology. 2017 [citado 2019 Dic 15]. Disponible en:https://www.hopkinsmedicine.org/kimmel cancer ce nter/centers/pediatric oncology/becoming our patient/ cancer types/germ cell tumors.html

[9] Cystic Teratoma Clinical Presentation: History and Physical Examination [Internet]. Cystic Teratoma Clinical Presentation: History and Physical Examination. 2019 [citado 2019 Dic 2]. Disponible en: https://emedicine.medscape.com/article/281850-clinical

[10] Tratamiento de tumores de células germinales del ovario [Internet]. American Cancer Society. [citado 2019 Dic 15]. Disponible en: https://www.cancer.org/es/cancer/cancer-deovario/tratamiento/tumores-de-las-celulasgerminales.html 